\title{
O FENÔMENO DO ENCARCERAMENTO DO SÉCULO XIX À SEGUNDA METADE DO SÉCULO XX E A BUSCA PELA SUPERAÇÃO DO FALSO DISCURSO DE DIREITO À SEGURANÇA E FORTALECIMENTO LEGAL
}

\author{
THE INCARCERATION EVENT FROM XIX CENTURY UNTIL THE SECOND \\ HALF OF XX CENTURY AND THE SEARCH FOR OVERCOMING THE FALSE \\ SPEECH OF RIGHT TO SECURITY AND STRENGTHENING OF LAW
}

${ }^{1}$ Tiago de Souza Fuzari

\section{RESUMO}

O trabalho propõe-se a analisar, a partir de uma metodologia histórico-analítica, o fenômeno do encarceramento ao longo da história moderna, bem como delineia os seus fatores determinantes para, assim, atingir o seu escopo de desmistificar a ideia de que o caminho para o combate à criminalidade restringe-se ao encarceramento e evidenciar sua relação com os movimentos de precarização dos direitos sociais e econômicos. Na busca pelo atingimento de tal desiderato, o esforço analítico do texto, em um primeiro momento, direciona-se a uma reconstrução historiográfica dos elementos formadores do Estado liberal, para desse modo analisar, de maneira mais detida, as influências socioeconômicas e as influências da forma como o direito era visto, à época, no processo massificado de encarceramento. Uma vez realizado esse primeiro objetivo, o esforço do texto verte-se para a análise da retomada de tal processo, verificado a partir dos anos de 1980, relacionando-o com as influências do pensamento neoliberal e da política e ideologia da "Lei e Ordem".

Palavras-chave: Encarceramento, Estado liberal, Neoliberalismo, Lei e ordem

\begin{abstract}
The research intend to analyze, using a historical-analytical method, the incarceration event over modern history and identify its determinative elements. To thus achieve its scope to demystify the idea that the way to oppose the crime is restricted to incarceration and shows yours the relationship with precarious movements of social and economic rights. For to do that, the text shows, in the first moment, the historical reconstruction of the liberal state, for identify how the socio economic occurrences and how the law view from that time exercised some influence in the incarceration event. After to do that first objective, the text tries to analyze incarceration that started again in the 1980 decade and relates it with the influences of neoliberal thought and "Law and Order" politics.
\end{abstract}

Keywords: Incarceration, Liberal state, Neoliberalism, Law and order

\footnotetext{
${ }^{1}$ Mestre em Direito pela Faculdade de Direito do Sul de Minas - FDSM, Pouso Alegre - MG (Brasil). Professror da Faculdade de Direito do Sul de Minas - FDSM, Pouso Alegre - MG (Brasil).

E-mail: tiagofuzari.adv@gmail.com
} 


\section{INTRODUÇÃO}

O texto constitui-se, inicialmente, em uma tentativa de delinear as características do direito e da economia na modernidade sob a sua faceta liberal, demonstrando assim que o Estado que se erigiu a partir das revoluções burguesas criou um direito classista que se pautava por uma igualdade e uma liberdade, as quais se efetivavam apenas no plano formal e que se constituía em uma economia de mercado que fomentava a exploração das massas de trabalhadores e em uma sociedade industrial marcada por uma profunda cisão. Somente a partir do estabelecimento das referidas premissas, estará estabelecido o necessário arcabouço de elementos para que se enfrente o fenômeno do encarceramento em massa verificado no século XIX.

Superada essa primeira noção introdutória, intentar-se-á uma apreciação dos motivos que levaram o século XIX a figurar como o século do encarceramento, sendo que, para tanto, o escopo analítico será vertido para a forma como se lidou com a criminalidade erigida da cisão social decorrente de um direito classista e segregador e de uma economia marcada pela profunda exploração; evidenciando, desse modo, que, em nome da preservação do modelo econômico liberal, desenvolveu-se uma criminologia que buscava os fatores originários da criminalidade no indivíduo/delinquente, dissociando, desse modo, a criminalidade dos fatores econômicos e sociais. Assim, o cárcere e os manicômios apresentaram-se como grandes armas no intento moderno de subjugação do indivíduo para que este servisse de força de trabalho, sustentando, desse modo, o ideário liberal.

Por fim, o texto, a partir da identificação da retomada do encarceramento na década de 1980, buscará os fatores associados à sua causa, destacando-se o movimento do capital transnacional, das frações ditas modernizadoras da burguesia e dos altos escalões dos Estados em levarem a cabo políticas de precarização do trabalho e desregulação social, fazendo surgir assim um ideário neoliberal e, juntamente com ele, a disseminação da chamada política e ideologia da "Lei e da Ordem" associada a um discurso de direito à segurança e ao fortalecimento legal, o qual se espalha pelos diversos países sob a influência estadunidense como forma de combater toda a insegurança e instabilidade social que afeta as classes mais débeis e que se veem vulneráveis ante a precarização das ações afirmativas desse Estado, demonstrando assim que, como em um movimento pendular da história, se adota o encarceramento como forma de solução para a criminalidade. 
Trata-se de um trabalho eminentemente teórica, baseando-se em pesquisa bibliográfica que se pautou por uma metodologia histórico-analítica.

\section{O ESTADO LIBERAL E SEU CONTRIBUTO NA FORMAÇÃO DE UM DIREITO CLASSISTA E UMA SOCIEDADE SEGREGADORA.}

A abordagem acerca de questões envolvendo o sistema penitenciário e o fenômeno do encarceramento exige uma retomada historiográfica com vistas a compreender os pensamentos que serviram de base para a formação da criminologia e do Direito Penal, tal fato faz com que a análise seja vertida para o surgimento e a evolução do Estado moderno, analisando-o em suas diferentes facetas, uma vez que os elementos ideológicos nele presentes mostraram-se determinantes na seleção de como e quem seriam os clientes desse sistema penitenciário, além de terem influência na forma como o sistema penitenciário e a própria atuação estatal de combate ao crime apresentam-se na atualidade.

Assim, o esforço do texto inicia-se no baixo medievo, momento que se verificou o desenhar do surgimento do Estado moderno, vez que um ascendente grupamento social denominado burguesia, cujo poderio econômico adveio da intensificação das relações comerciais, uniu-se à nobreza, em um movimento de centralização de poder. O resultado foi o estabelecimento de uma configuração estatal sem paralelos na história, está aqui se falando do surgimento do Estado moderno, cujo advento representou a configuração de uma nova realidade, calcada na ideia de centralização e institucionalização. ${ }^{1}$

Viu-se, nesse passo, a transferência da autoridade e dos recursos administrativos, bélicos e financeiros das mãos do particular - dos diferentes e pulverizados núcleos de poder presentes no medievo - para as mãos, em um primeiro momento, do príncipe absoluto, inaugurando-se o Estado moderno sob a sua primeira faceta, o Estado absolutista. No plano econômico, esse cenário de centralização fez com que o mercantilismo florescesse e, embora se tenha preservado o capital agrário, fomentou-se o poder burguês, o qual se ancorava no capital móvel financeiro; de modo que, conforme aduz Mário Lúcio Quintão Soares, o Estado

\footnotetext{
1 MORAIS, José Luis Bolzan de; STRECK, Lenio Luiz. Ciência política e teoria do estado. 6. ed. Porto Alegre: Livraria do Advogado, 2008 . 
centralizado e seus órgãos onipotentes funcionavam a serviço da sociedade burguesa que fortalecia e consolidava seu poder. ${ }^{2}$

Em um primeiro momento, a partir do deslinde histórico carreado, pode-se verificar que o Estado moderno, em sua primeira conformação, não se estabeleceu de maneira equânime ou de modo a atender variados interesses; ao contrário, pode-se de antemão verificar que este se estabeleceu comprometido com determinados interesses, ou seja, nasceu ele comprometido com os ideais daqueles grupamentos que o constituiu, nobreza e burguesia, sendo, portanto, o Estado da classe dominante e para ela esse Estado funcionava.

O estabelecimento do Absolutismo e o consequente desenvolvimento mercantil acarretaram um substancial aumento de poder dessa classe burguesa e, neste ponto, essa parcialidade do Estado e a consonância de uma ótica classista atrelada a seus movimentos vêm à tona; pois, em um dado momento, passou a burguesia a ver, na figura do monarca, um empecilho para seu próprio desenvolvimento, haja vista que o sistema absolutista não era capaz de prover a necessária segurança jurídica exigida pela intensificação comercial, tampouco podia a tão poderosa burguesia conviver com as despóticas intervenções do Estado no âmbito jurídico-patrimonial, além das intervenções discricionárias e imoderadas no ordenamento jurídico vigente. ${ }^{3}$

Assim, tratou a burguesia de se colocar a frente de uma série de revoltas que levaram abaixo todo o poderio real, por meio da avassaladora força das chamadas revoluções burguesas, tendo por mais emblemática delas a Revolução Francesas de 1789 que, sob os motes de igualdade, liberdade e fraternidade conseguiu insuflar as massas rumo à destruição do Estado Absolutista e inaugurou a era do Estado de direito, bem como a faceta liberal da modernidade. Verificando-se, pois, que a burguesia, a qual outrora apresentava-se como classe dominada ou de menor importância ante os poderes da nobreza e respectivamente do monarca, formulou os princípios filosóficos de sua própria revolta social, tornando-se a classe dominante. ${ }^{4}$

Nesse processo, construiu-se o ideário que é emblematicamente retratado na obra "A Liberdade Guiando o Povo" de Eugène Delacroix, no qual a burguesia e as massas uniam-se na busca pela liberdade; rompendo, dessa forma, com o despótico regime absolutista para criar uma nova forma de organização estatal que se constituiria em um Estado de Direito, regido por uma constituição, com tripartição de poderes, garantia das liberdades individuais,

\footnotetext{
SOARES, Mário Lúcio Quintão. Teoria do estado: paradigmas em face da globalização. 3. ed. São Paulo: Atlas, 2008. p. 79-80.

3 Ibidem, p. 192.

4 BONAVIDES, Paulo. Do Estado Liberal ao Estado Social. $8^{\text {a }}$ ed. São Paulo: Malheiros, 2007. p. 30.
} 
proteção absoluta da propriedade privada e, acima de tudo, segurança jurídica, a fim de se efetivar a promessa de uma sociedade com oportunidades para todos, liberdade e igualdade, livre mercado e economia democratizada, fundando-se na máxima de que somente garantindo a não intervenção do Estado no âmbito privado seria possível ao individuo valer-se de todas as suas possibilidades para se desenvolver. ${ }^{5}$

O Estado liberal, trajando todo esse aparato ideológico, nos quais se fundaram as revoluções burguesas, traduziu-se, notadamente em decorrência da segurança jurídica e da não intervenção nas questões privadas, em um vultoso desenvolvimento econômico, estabelecendo-se a mão invisível no controle de um mercado concorrencial que, a despeito das cíclicas crises capitalistas, enveredou por um vertiginoso caminho de crescimento, trazendo consigo a chamada Revolução Industrial que deu asas ao surgimento de rentáveis fábricas movidas pela força de trabalho de um grande número de operários, os quais se amontoavam em seus arredores, formando as cidades fabris que se edificavam como um grande monumento da cisão social existente há época.

O vultoso desenvolvimento econômico não ocorreu de maneira a abarcar os diferentes grupamentos sociais, concentrando-se nas mãos da burguesia, que outrora havia insuflado as massas a lutarem contra o monarca absolutista. Tal concentração de capital acarretou uma progressiva deterioração do quadro social, situação esta denominada de "Questão Social" ou "Luta de Classes", , de modo a fazer com que a massa trabalhadora fosse levada à extrema penúria.

Criou-se, dessa forma, uma sociedade cindida entre uma massa marginalizada, representada pelos trabalhadores que viviam na miséria, submetidos a degradantes condições trabalho e que conviviam com um exército de reserva que servia de joguete nas mãos dos burgueses neste movimento de precarização do trabalho e, de outro lado, via-se a figura do típico burguês que, graças ao poder econômico e político que estava concentrado em suas mãos, gozava do bom e do melhor que o mundo liberal poderia oferecer, vivendo nos subúrbios arborizados, longe da fuligem e das epidemias que abatiam e dizimavam os conjuntos habitacionais. ${ }^{7}$

A partir da análise do deslinde histórico erigido, é possível verificar o viés classista impregnado na formação do Estado moderno, fato este que acabou por fazer com que o Estado liberal se estruturasse de modo a atender os anseios da classe burguesa, constituindo-

\footnotetext{
5 SOARES, Mário Lúcio Quintão. Op. cit., p. 188.

6 FERREIRA FILHO, Manoel Gonçalves. Direitos Humanos Fundamentais. 11. ed. São Paulo: Saraiva, 2009. p. 42

7 Ibidem, p. 43.
} 
se em um instrumento a seu serviço, uma vez que os motes revolucionários foram implementados apenas em seu sentido formal, era-se igual e livre em essência. Ou seja, tratava-se de uma igualdade e liberdade perante a lei e diante do Estado, o qual se portava como mero vigia da ordem social, reduzindo seus préstimos a meros direitos de defesa/direitos negativos. Assim todos eram livres e iguais, mas apenas os detentores do capital eram efetivamente capazes de se valerem de todas as suas possibilidades para realizarem suas conquistas pessoais. ${ }^{8}$

Nesse passo, aduz Paulo Bonavides ${ }^{9}$ que trouxe o Estado liberal a mais profunda contradição dialética do Estado moderno, uma vez que a burguesia nada mais fez, a partir de suas revoluções, que generalizar doutrinariamente ideais de uma única classe como comuns a todas as classes. Tal grupamento social despertou nas massas a consciência de suas liberdades políticas; no entanto, no momento em que se apoderou do controle político da sociedade, já não tinha interesse em manter, na prática, a universalidade dos emblemáticos ideais que levaram o povo para as ruas e que puseram fim ao Estado absolutista, conservando-os apenas no plano formal. Fez-se, dessa maneira, a doutrina de uma classe como doutrina de todas as classes.

Nesse cenário, o direito aparece - visto logicamente a partir do discurso liberal vigente - como o bastião da neutralidade, apresentando-se como mero instrumento do controle social, uma vez que apenas trata dos conflitos sociais de modo objetivo, procurando pacificar a sociedade; no entanto, não se pode fechar o olhos para a parcialidade com que o próprio Estado se estruturou, bem como os anseios que busca atender. Isso direciona a análise para o nascedouro do direito, o qual se formou comprometido com a ordem liberal burguesa em ascensão, afigurando-se como grande aliado das elites detentoras de riquezas, de modo a justificar os grandes sistemas de pensamentos e legitimar as grandes teorias, assumindo, desse modo, fundamental papel na estruturação da arquitetura moderna. ${ }^{10}$

No entanto, todo esse caráter classista fora bem disfarçado pelo discurso liberal, criando-se um aparente cenário ideológico, no qual todos eram livres e iguais; porém, por detrás do discurso vigente, a realidade trazia um direito liberal apenas para o homem branco,

\footnotetext{
8 SOARES, Mário Lúcio Quintão. Op. cit., p. 194.

9 BONAVIDES, Paulo. Op. cit., p. 30.

${ }^{10}$ BITTAR, Eduardo C. B. O direito na pós-modernidade. 2. ed. Rio de Janeiro: Forense Universitária, 2009. p. 58
} 
uma democracia que se restringia apenas aos homens brancos e ricos e uma economia que oferecia oportunidade para poucos. ${ }^{11}$

A compreensão do quadro socioeconômico da época, bem como a dinâmica excludente de uma economia de mercado que se alimentava da exploração das massas mostram-se elementares para que seja possível uma análise acerca do processo de massificação do encarceramento verificado no século XIX, uma vez que somente a partir da construção de um direito classista, uma igualdade e liberdade existente apenas no plano formal e uma sociedade industrial marcada por uma profunda cisão, foi possível criar o cenário para que tal fenômeno se desenvolvesse, conforme será adiante demonstrado.

\section{DIREITO, PRISÕES E CRIMINALIDADE DO FINAL DO SÉCULO XIX AO INÍCIO DO SÉCULO XX}

Atualmente, paira como algo natural e indispensável à ideia de que a punição do indivíduo por parte do Estado esteja associada às prisões; no entanto, o encarceramento como forma de punição encontra suas raízes firmadas na modernidade, sendo que, até o inicio do século XVIII, a privação de liberdade tinha por fim precípuo a detenção do indivíduo, quando este fosse considerado suspeito ou culpado, até que fosse possível a aplicação de sua sentença.

A sentença, por sua vez, não tinha o condão de restringir a liberdade, mas sim recair sobre o corpo da pessoa considerada culpada, de modo que ela se materializava ou se cumpria por meio de chicotadas, marcas de ferro, pelourinho, mutilações, torturas e trabalhos forçados. Cumpre salientar que isso não se dava por acaso, tal situação ocorria, pois a ideia de liberdade inerente ao indivíduo e o próprio reconhecimento do indivíduo em si foram construídos ao longo da modernidade, notadamente após as revoluções burguesas. Desse modo, não havendo outro suporte para pena ou não havendo o que se retirar da pessoa, tinha a pena que recair sobre o corpo daquele que era considerado delinquente. $\mathrm{O}$ advento do o ideário liberal trouxe, em seu bojo, o individualismo, passando o homem, cada vez mais, a ser visto como unidade, como indivíduo, tendo reconhecida a sua identidade própria. ${ }^{12}$ Isso acarretou o surgimento dos ideais de proteção à integridade física, bem como o asseguramento da liberdade e

\footnotetext{
11 MAGALHÃES, José Luiz Quadros de. Comentário do filme "A Vila" 28 jun. 2010. Disponível em < http:// joseluizquadrosdemagalhaes.blogspot.com.br/2010/06/comentario-do-filme-vila.html>. Acesso em 30 mar. 2014.

SOARES,

Mário

Lúcio

Quintão.

Op.

cit.,

194-196.
} 
igualdade, ainda que sob uma faceta formal, de modo a transformar o encarceramento per se em punição.

Não só a forma de punir sofreu alteração com as mudanças trazidas pelo Estado moderno, devendo-se deslocar a atenção para a crescente cisão social que se desenvolveu juntamente com a prosperidade econômica decorrente do liberalismo, conforme acima já aduzido. Assim, em uma sociedade, cuja maior parte da população vivia na penúria, em uma realidade de sistemática precarização do trabalho e contínua concentração de renda; viu-se, por consequência, uma modificação no próprio ambiente urbano, criando-se cortiços e locais insalubres de moradia, nos quais homens, mulheres e crianças partilhavam intimidades e sobreviviam a extenuante rotina de exploração imposta pela sistemática liberal.

O desenvolvimento da criminalidade foi algo inevitável no referido cenário e o Direito, por sua vez, embora se apresentasse como instrumento neutro de controle social, estava comprometido com a ordem burguesa liberal vigente, tratando logo de buscar proteger o patrimônio e a riqueza, além de despertar o repudio ao ilegalismo, de maneira a desempenhar um papel fundamental na nova arquitetura moderna. ${ }^{13}$ Nesse passo, as prisões erigiram-se como grande instrumento no intento moderno de docilização dos corpos para servirem como força de trabalho, sustentado assim o ideário liberal. ${ }^{14}$

Com efeito, o século XIX figurou como o século do encarceramento, no qual se viu a segregação física daqueles considerados não adaptados, ou seja, aqueles que não serviam à força de trabalho e ameaçavam/incomodavam o patrimônio e seus detentores. Tratavam-se de pessoas para quem o liberalismo econômico não trouxe a esperada democratização da economia, tampouco concretizou/materializou a igualdade e a liberdade, tendo elas como destino os estabelecimentos de internação coletiva como os presídios e os manicômios. ${ }^{15}$

Passando-se a uma análise mais detida acerca da relação entre o liberalismo econômico desenvolvido no século XIX, a tremenda cisão social e o grande número de encarceramento, verifica-se um verdadeiro movimento de encobrimento do real, no qual se tentou resguardar o sistema econômico e aqueles que dele se aproveitavam, tendo em vista que o liberalismo econômico trouxe consigo uma sistemática concentração de capital e uma consequente exclusão e desigualdade. Tal fato, por sua vez, fomentava o surgimento da criminalidade.

${ }^{13}$ BITTAR, Eduardo C. B. Op. cit., p. 58-59.

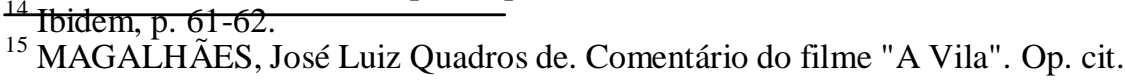


No entanto, não se podia mexer no sistema econômico, pois isso afetaria a riqueza e o poder da classe dominante que lucrava com o modelo e com toda a exploração dele decorrente. Assim, o cerne do problema enfrentado relacionava-se a como resolver a questão da criminalidade e, ao mesmo tempo, não alterar o sistema econômico. O caminho trilhado foi no sentido da separação ou desconexão do sistema econômico-social da criminalidade. Isso se constituiu no acobertamento do real, conforme acima mencionado, de modo que o estudo da criminalidade passou a se debruçar sobre o indivíduo, desprezando, dessa forma, os fatores econômico-sociais inerentes à questão. ${ }^{16}$

Tal forma de pensamento predominou entre a segunda metade do século XIX e início do século XX e fez nascer uma criminologia, cujo foco analítico vertia-se ao indivíduo, de modo que seu objetivo restringia-se a individualizar as causas e os diversos fatores do comportamento criminoso para combatê-los por meio de uma prática que tendia, sobretudo, a modificar o delinquente. Frisa-se, nesse passo, que tais fatores ou causas da criminalidade passaram a ser buscadas no indivíduo ${ }^{17} \mathrm{e}$ não nos problemas decorrentes de um modelo econômico e dos problemas sociais dele advindos.

Destaca-se assim, como expressão máxima dessa forma de estudo e análise da criminalidade a criminologia positiva, sob a sua vertente antropológica, a qual se inspirava na psicologia e na filosofia positivo naturalista. Tinha ela por pretensão individualizar sinais antropológicos da criminalidade e, para isso, utilizava-se do cárcere e dos manicômios como zonas apartadas da sociedade para observação; ${ }^{18}$ era, pois, a criminologia eminentemente centrada no indivíduo.

Passando-se a criminalidade exclusivamente para os ombros do criminoso, gradativamente se criou um movimento de sistemática construção de presídios, manicômios, aumento de penas, diversificação de tratamentos e expansão das patologias, fazendo com que se criasse a consciência de que a verdadeira solução do problema da criminalidade e o problema da segurança não perpassassem pelas questões socioeconômicas, mas se restringisse apenas ao cárcere. Tal pensamento fez com que se enveredasse por um problema semântico, comumente ignorado, o qual consiste no fato de se colocar o controle como sinônimo de solução. O cárcere é forma de controle e o controle controla; logo, ele não soluciona. Ao se

\footnotetext{
16 MAGALHÃES, José Luiz Quadros de. Comentário do filme "A Vila". Op. cit.

17 Ibidem.

18 BARATTA, Alessandro. Criminologia Crítica e Crítica do Direito Penal: introdução à sociologia do direito penal. $3^{\mathrm{a}}$ ed. Rio de Janeiro: Revan,

2002.

p. 
colocar o controle como forma de solução, o que se consegue é apenas a manutenção da situação como ela se encontra. ${ }^{19}$

Essa série de fatores acima elencados, os quais perpassam por uma forma de garantia de direitos apenas no plano formal, aliados a uma economia liberal, acompanhada de uma sistemática precarização do trabalho e concentração de renda, além de uma criminologia, cujo foco analítico verte-se preponderantemente ao indivíduo na busca pela solução da criminalidade, em detrimento de fatores socioeconômicos, fizeram com que o século XIX figurasse como o século do encarceramento.

Forçoso salientar, por fim, que o progressivo agravamento das crises sociais decorrentes do nível insustentável de exploração vivido pelas massas, forçaram as classes dominantes a cederem ante aos movimentos sociais que começaram a insurgir contra o modelo de exploração que havia se institucionalizado e a estruturação oligárquica que havia se instalado no seio do Estado liberal. ${ }^{20}$ Isso levou o Estado a tomar para si obrigações prestacionais com vistas à implementação/materialização de direitos, nascendo, deste modo, os chamados Direitos sociais que por se vincularem a esse contexto específico localizado temporalmente entre o fim do século XIX e início do século XX e por decorrem de um percurso de lutas de cunho emancipatório caracterizam-se por ser direitos históricos. ${ }^{21}$ Assim, diferentemente da posição absenteísta do Estado liberal, o que se passou a ter foram prestações positivas (materiais) realizadas pelo Estado de maneira direita ou indireta, com vistas a possibilitar melhores condições vida aos indivíduos mais fragilizados do ponto de vista social. ${ }^{22}$ Tal fato acabou por inaugurar a faceta social do Estado na modernidade.

O advento do Estado social e a implementação desses direitos fizeram com que a ideia de prisão entrasse em um longo eclipse, ${ }^{23}$ devendo-se destacar, no ramo da criminologia, as teorias que se ergueram para combater a antropologia lombrosiana, de modo a trazer elementos externos ao indivíduo, assim chamados de fatores exógenos, os quais se mostravam, segundo eles, mais importantes na determinação do delito que propriamente aqueles cuja vinculação circunscrevia-se eminentemente à pessoa, ${ }^{24}$ mas se deve ressaltar que isso não significou que tenha a criminologia efetivamente se desvinculado de uma análise centrada no indivíduo, embora outros fatores tenham sido carreados em seu desenvolvimento.

\footnotetext{
19 MAGALHãES, José Luiz Quadros de. Comentário do filme "A Vila". Op. cit.

${ }_{21}^{20}$ BEÇAK, Rubens. Democracia: hegemonia e aperfeiçoamento. São Paulo: Saraiva, 2014. p. 25.

21 GOTTI, Alessandra. Direitos sociais: fundamentos, regime jurídico, implementação e aferição de resultados.

São Paulo: Saraiva, 2012. p. 46-47.

22 SILVA, José Afonso da. Curso de Direito Constitucional Positivo. 25 a ed. São Paulo, 2005. p. 286.

23 WACQUANT, Luïc. As duas faces do gueto. São Paulo: Boitempo, 2008. p. 97.

24 FERNANDES, Newton; FERNANDES, Valter. Criminologia Integrada. $2^{\mathrm{a}}$ ed. São Paulo: Revistas dos Tribunais, 2002. p. 98.
} 
Desse modo, somente na década de 1980, com a difusão de um ideário conservador neoliberal verificou-se a retomada do encarceramento e o reforço da visão de que a prisão se afiguraria como a forma de combate à criminalidade.

\section{O NEOLIBERALISMO E A RETOMADA DA FALSA CONCEPÇÃO DO ENCARCERAMENTO COMO FORMA DE SOLUÇÃO PARA A CRIMINALIDADE}

A década de 1980, conforme acima mencionado, verificou uma retomada do encarceramento como forma de combate à criminalidade e nesta empreita pela compreensão de tal fenômeno, valer-se-á este texto de dados e elementos presentes na obra "As duas faces do gueto" do autor Luïc Wacquant. ${ }^{25}$ Nesse sentido, a marcha textual prossegue, a partir deste ponto, com a advertência de que não pode o fenômeno do encarceramento ser visto de maneira apartada da realidade socioeconômica e que o texto jogará o texto luz em uma análise centrada especificamente nos Estados Unidos da América e na Europa, mais precisamente no Reino Unido, uma vez que representam eles respectivamente os pontos de origem e difusão de uma sistemática neoliberal, a qual veremos à frente que se relaciona com a retomada do encarceramento.

Acerca do sobredito movimento neoliberal, tratou-se ele de um fenômeno sui generis, cujas raízes remontam ao liberalismo clássico, contudo pode-se delinear que, enquanto o liberalismo clássico tinha por escopo uma ruptura com premissas absolutistas e medievais que o antecedera, o neoliberalismo insurge-se contra a figura do Estado em sua face totalitária, sua face comunista e, primordialmente, contra o Estado de bem-estar social. Afigura-se, desta maneira, como uma reação teórica aos modelos europeus de Estado de bemestar social e à política estadunidense do New Deal. Tal reação teórica, cujo maior expoente pode-se destacar Friedrich Hayek, já se desenhava no período pós-guerra, mas diante da pujança dos Estados sociais nunca ganhou significatica acolhida. Porém, quando mais uma das cíclicas crises do capitalismo começou a rondar a década de 1970 e os Estados sociais começaram a apresentar problemas fiscais, o pensamento neoliberal ganhou força. Dentre os elementos que o embasavam nesta ruptura com a figura de um Estado atuante do ponto de

\footnotetext{
25 WACQUANT, Luïc. Op. cit.
} 
vista da materialização de direitos está o fato da preponderância estatal ser vista como uma forma de limitação das liberdades individuais. ${ }^{26}$

Tal processo de afastamento dos ditames do Estado social ocorreu de maneira gradual e com intensidades diferentes nos vários países, mas como já asseverado, pode-se determinar que figuraram como pontos de origem e irradiação os Estados Unidos da América e o Reino Unido, os quais se colocaram, a partir das décadas de 1970 e 1980, como grandes defensores do mercado desregulado, devendo-se mencionar a influência emanada do Consenso de Washington, datado de 1989. O interesse em desmontar décadas de legislação social e supervisão econômica também se verificou em países como Nova Zelândia, Dinamarca, França e Brasil, que, embora distantes, apresentaram e apresentam sazonais interesses no sobredito pensamento. ${ }^{27}$

Voltando-se os olhos aos países epicentro deste movimento, notadamente os Estados Unidos da América, verificava-se, na década de 1980, um plano de fundo de progressivo empobrecimento e desemprego da população, mas em um movimento contrário à lógica desenvolvida na primeira metade do século XX, pôde-se constatar uma progressiva tendência de busca pelo enxugamento da atuação estatal, de modo que o capital transnacional, as frações ditas modernizadoras da burguesia e os altos escalões do Estado encabeçavam movimentos de desregulação social e uma escalada na precarização do trabalho assalariado. Diante da desordem social decorrente da insegurança gerada pelo afastamento do Estado, viu-se estabelecer, como resposta, um controle punitivo rígido. Assim, o cenário que se desenhou caracterizava-se pela substituição/precarização dos sistemas públicos de saúde, previdência e educação, por um forte aparato policial, cortes e um sistema prisional, que se apresentavam de modo cada vez mais presente e mais intrusivo na vida das classes e grupos que outrora dependiam de uma atuação prestacional positiva por parte do Estado. ${ }^{28}$

Essa nova sistemática orientou-se a partir de um discurso difundido e acolhido de maneira bastante sólida no seio social, o qual pregava o "direito à segurança" e o "fortalecimento legal", legitimando, assim, o encarceramento em massa. Tal encarceramento se fazia premente ante a necessidade do controle da insegurança social gerada pelas medidas de enxugamento do Estado (destaca-se que, embora fosse essa a finalidade, a relação existente entre a insegurança afastamento do Estado não era abertamente declarada). Viu-se ainda a privatização de presídios, bem como o desenvolvimento de uma intolerância com as camadas

\footnotetext{
26 GENNARI, Adilson Marques; OLIVEIRA, Roberson de. História do pensamento econômico. São Paulo: Saraiva. 2009 . p. 321 - 323.

27 JUDT, Tony. Um tratado sobre nossos actuais descontentamentos. Lisboa: Almedina, 2012. p. 27.

28 WACQUANT, Luïc. Op. cit., p. 93.
} 
mais débeis da sociedade, ${ }^{29}$ além do consequente agigantamento da população carcerária como, no caso estadunidense em que se verifica, na primeira década deste século, uma população carcerária que ultrapassa os dois milhões e setecentos mil detentos. ${ }^{30}$

A partir da hegemonia deste novo pensamento, viu-se que o encarceramento passou a ter um emprego voltado à exclusão de categorias sociais consideradas indesejadas, mas obviamente isso não se punha de modo aberto e declarado, servindo ele para a perseguição de determinados seguimentos sociais, podendo-se citar o caso europeu em que se direcionou o aparato penal para a perseguição aos estrangeiros não europeus originários das ex-colônias, de maneira a reafirmar o sentimento de não integração destes ao corpo social. Ou ainda o caso estadunidense em que o aparato penal é empregado para o controle e contenção das camadas consideradas inferiores e que não devem se misturar, como é o caso dos negros que, desde de 1989 , correspondem à metade das novas admissões nas prisões. ${ }^{31}$

Conforme já aludido em parágrafos acima, esse conjunto de modificações relacionadas às ações prestacionais do Estado, bem como esse movimento de retomada do encarceramento inscrevem-se no bojo do pensamento neoliberal, o qual se firmou a partir da década de 1980, defendido por grupos que lutavam pela redução das prerrogativas das coletividades perante o mercado e que buscavam a construção de um o mercado de trabalho desregulado e desqualificado, mantendo-se a situação sob controle por meio de um aparato estatal onipotente e intrusivo. Justamente por isso, verificou-se no contexto neoliberal a progressiva criminalização dos movimentos sociais.

O resultado desse novo rearranjo foi a formação de uma maquinaria estatal voltada à administração da pobreza, uma vez que se firmou o comprometimento com a construção de um Estado que busca desmantelar o Estado social e fortalecer o Estado penal em um ambiente que marcha para o desemprego das massas e para uma paulatina precarização do trabalho. Nesta fórmula, a mão invisível do mercado e o punho de ferro do Estado combinam-se para fazer as classes mais débeis submeterem-se a um trabalho assalariado dissocializado e à instabilidade social. A prisão e o aparato penal ressurgem como a instituição responsável pela manutenção dessa ordem social em favor das classes dominantes por meio da consequente criminalização da pobreza. ${ }^{32}$

\footnotetext{
29 WACQUANT, Luïc. Op. cit., p. 94.

30 MAGALHÃES, José Luiz Quadros de. Privatizar o sistema carcerário? Disponível em <http:// joseluizquadrosdemagalhaes.blogspot.com.br/2010/08/privatizar-o-sistema-carcerario.html> Acesso em 30 mar. 2014.

32 WACQUANT, Luïc. Op. cit., p. 95.

32 Ibidem, p. 96.
} 
A partir da necessidade de fortalecimento de um Estado penal, que se mostrava como elemento de controle de toda a instabilidade social decorrente das medidas afetas ao neoliberalismo, verificou-se, nos Estados Unidos da América, a elaboração, estabelecimento e difusão para os demais países de um discurso de criminalização das camadas mais débeis da sociedade, o qual se embasava na chamada ideologia e política da "Lei e Ordem". Como asseverado, trata-se de uma ideologia que apresenta por fim precípuo uma perseguição às classes mais débeis da sociedade, a partir de um discurso encobridor do seu real objetivo, de modo que propaga a ideia de direito à segurança, vertendo, contudo, o aparato estatal para crimes decorrentes da instabilidade social acarretada pela precarização do trabalho e desmantelamento do Estado social. Estabeleceu-se, portanto, uma guerra contra os pobres e marginalizados. $^{33}$

Dito isso, vê-se que não se cria uma efetiva guerra contra a criminalidade de maneira geral, ou uma tolerância zero, nomenclatura essa também associada à ideologia da "Lei e Ordem", mas sim uma seletividade nos crimes que se quer combater. Tal seletividade ocorre, tendo em vista que esse rigor punitivo do Estado penal, que se busca construir, não se direciona com a mesma alacridade aos crimes de colarinho branco, às fraudes, aos desvios de dinheiro, à poluição ilegal, à violação da legislação de emprego e saúde; de modo a demonstrar que o objeto dessa política, muito mais que combater o crime, é fomentar uma guerra/combate contra um alvo muito específico, qual seja, os pobres e marginalizados. Curioso salientar que nos Estados Unidos da América tal política ganhou o nome de "medidas de qualidade de vida", no entanto, em um movimento de encobrimento do real, tal nomenclatura parece zombar dos negros, pobres e latinos a quem toda essa ideologia neoliberal associada à severidade punitiva mostra-se apenas com um viés precarizador de suas vidas.

Antes de se enveredar por um aparte mais detalhado acerca dos mecanismos de encobrimento do real, afetos a todo esse arcabouço ideológico, forçoso que se faça uma breve análise sobre a forma de surgimento e difusão da política e ideologia da "Lei e Ordem", a qual teve por origem instituições estadunidenses como Manhattan Institute e America Emterprise Institute que trataram de elaborar e disseminar tais pensamentos na classe dominante e, a partir da atuação do então prefeito da cidade de New York, Rudolph Giuliani, fez com que a cidade virasse o grande símbolo da segurança, concretizando, assim, o seu primeiro momento de elaboração e implementação da política em análise.

33 WACQUANT, Luïc. Op. cit., p. 102. 
A partir da relação entre os think tanks dos institutos estadunidenses e europeus, viuse a política e ideologia da "Lei e Ordem" atingir e se difundir na Europa, destacando-se o fundamental papel da Inglaterra neste cenário. A partir desse ponto, verificou-se uma progressiva adesão espontânea de intelectuais que a reforçavam e garantiam a "capa cientifica" necessária por meio de sua autoridade acadêmica, fazendo com que a sociedade a incorporasse com mais força. ${ }^{34}$

Isso não significa dizer que a Europa tenha aderido de maneira absoluta à forma de atuação repressiva estadunidense, visto que preserva ela ainda determinadas medidas de bemestar social, o que evita, de certo modo, a instabilidade social vivenciada pelos Estados Unidos da América. No entanto, não se sabe se isso é um novo caminho - uma alternativa europeia - ou apenas um estágio na trilha do encarceramento em massa. Na América Latina, por sua vez, ocorre uma massiva adesão ao estilo estadunidense, e isso traz graves consequências à sociedade, tendo em vista seus altos índices de pobreza e a baixa concretização dos programas de bem-estar social. Tal quadro mostra-se ainda mais agudo nas sociedades que vivenciaram experiências autoritárias, como no caso brasileiro e argentino, fazendo com que a aplicação dessa maior severidade do aparato penal associado às políticas neoliberais acabem por fomentar o poder das antigas elites ditatoriais e a submissão a elas das classes marginalizadas. ${ }^{35}$

Ante a todo esse direcionamento da atuação do aparato penal, a questão que se mostra pungente cinge-se ao fato de como as pessoas são levadas a agir contra seus próprios interesses, uma vez que todo esse discurso de direito à segurança apresenta significativa acolhida até mesmo no seio das massas por ele afetadas. Assim, é necessário que se jogue luz nos chamados mecanismos ideológicos de encobrimento do real, que são utilizados como grandes armas nessa empreita. Dentre eles pode-se destacar: a chamada "naturalização das coisas" que, por meio da massiva e sistemática repetição faz com que determinadas linhas de pensamentos postem-se como verdades. Tem-se ainda a "matematização da economia" que cultiva o entendimento de que a economia é algo técnico, matemático e não o resultado de uma decisão política, situação esta que acaba por fazer com que o estado das coisas se perpetuem e se aceite o desmantelamento do Estado social. Por fim, tem-se a "nomeação", talvez o mais preocupante 
dos mecanismos, pois é ela a responsável pela separação/segregação, impedindo que se veja o outro ser humano como pessoa. Por meio da "nomeação", classificam-se as pessoas em grupos (os judeus, os negros, os pobres) desumanizando-os, de modo a possibilitar que eles sejam perseguidos, uma vez que não se tem a visão de que tais grupos são formados por pessoas. ${ }^{36}$

Juntamente com isso difunde-se a ideia e cria-se um senso comum, de que o público é sempre ruim, ineficiente, incompetente e corrupto e o privado é eficiente; abrindo-se caminho para a dissociação do Estado e seus serviços, de modo a levá-lo às mãos do privado, valendo-se, neste ponto, a menção às privatizações do sistema carcerário. Tudo isso se materializa e se encobre por meio do discurso do direito à segurança e combate à criminalidade, de modo a criar e fomentar uma cultura de medo daquelas classes que são perseguidas, discurso este levado a cabo inclusive por aqueles que são vítimas de todo esse sistema. O resultado de tudo isso, como em um movimento pendular de retomada do que se viu no século XIX, é a utilização do superencarceramento por parte do Estado para administrar o "populacho" que incomoda e conter a insegurança social gerada pela precarização do trabalho e pelo desmantelamento do Estado social, ${ }^{37}$ cultivando, com isso, a falsa visão de que o encarceramento é a solução para a criminalidade.

Uma vez explicitada a dinâmica envolvendo a retomada do encarceramento iniciado nos anos de 1980 e que se espalha pelo mundo, chega-se, assim, ao ponto culminante da marcha textual, em que se pode vislumbrar uma concepção afeta à evitabilidade da adoção de um Estado penal, pautado pelo desmantelamento das conquistas do Estado social e carreada por linhas políticas e ideológicas que se estabelecem de modo a inviabilizarem qualquer outra alternativa de construção do Estado. Nesse sentido, verifica-se que, diversamente do que ocorre nos Estados Unidos da América, local onde a criminalização da pobreza aparentemente mostra-se plasmada à própria estrutura do Estado, na Europa e nos demais países o recurso ao aparato prisional não é um destino, mas sim uma escolha política e essa escolha precisa ser feita de maneira aberta com o real conhecimento dos fatos e de suas consequências. ${ }^{38}$

36 MAGALHÃES, José Luiz Quadros de. Privatizar o sistema carcerário? Op. cit. 37 WACQUANT, Luïc. Op. cit., p. 106.

38 Ibidem, p. 104.

Assim, a construção de uma alternativa a esse não fatídico destino de penalização da precariedade social deve ser feito por meio de movimentos em três campos diversos, a 
começar pelo campo semântico em que se deve desmistificar/desconstruir a concepção arraigada no atual cenário de debates de que o problema da insegurança é algo a ser tratado apenas sob a vertente penal de combate a criminalidade. Deve-se trazer ao cenário de discussões a influência gerada por questões de cunho social e econômico, bem como se deve afastar o tratamento banalizado da questão penal, dando-se a sua real dimensão em um cenário de valorização do indivíduo enquanto pessoa. O segundo ponto a ser desenvolvido refere-se ao reposicionamento da atuação política e judicial, as quais devem fomentar a utilização de medidas sociais, sanitárias e educativas em detrimento de medidas penais, retomando-se, desse modo, a ideia de que o encarceramento não constitui solução em sim mesmo, mas sim mera forma de perpetuação do status quo. Por fim, deve-se estreitar o laço entre os pesquisadores penais e sociais (sociologia) para uma melhor compreensão dos fenômenos sociais e uma melhor e mais eficiente atuação do aparato penal, ressaltando-se que o modo mais eficiente de se reduzir o encarceramento ocorre por meio do fortalecimento e expansão dos direitos sociais e econômicos. 39

\section{CONCLUSÃO}

Teve o presente texto por objetivo, utilizando-se, em um primeiro momento, de uma reconstrução historiográfica da modernidade sob a sua faceta liberal, analisar o fenômeno do encarceramento, erigindo assim os fatores que o determinaram e fizeram com que o século XIX afigurasse-se como o século do encarceramento, para, em um segundo momento, debruçar a análise em uma aparente repetição do referido fenômeno, a partir da década de 1980. Pôde-se, assim, verificar a sua ligação com o ideário neoliberal e a disseminação da política e ideologia da "Lei e Ordem", a qual, a partir de um discurso de direito à segurança e fortalecimento legal, direcionou a atuação do aparato penal para as classes mais débeis da sociedade, classes estas que foram colocadas em uma situação de fragilidade ante a precarização do trabalho e a desregulação social decorrentes do próprio neoliberalismo.

\footnotetext{
39 WACQUANT, Luïc. Op. cit., p. 105.
} 
A partir da referida análise será possível desmistificar a falsa ideia de que o caminho para o combate à criminalidade restringe-se ao encarceramento, bem como demonstrar que a precarização das medidas afetas ao Estado social e a formação de um Estado penal não se constituem em um inevitável destino dos vários Estados, tratando-se apenas de uma escolha política, escolha esta que precisa ser feita de maneira aberta com o real conhecimento dos fatores que a englobam e de suas consequências. Como contraponto a esse pensamento, é possível construir um movimento de valorização e expansão dos direitos sociais e econômicos que acarretaria, por conseguinte, em uma redução desse crescente processo de encarceramento de massas.

Espera-se que os argumentos esposados ao longo desse texto contribuam para incrementar a análise crítica do fenômeno do encarceramento, bem como o esforço teórico sirva de fundamento, mas, principalmente, de ponto de partida para a compreensão de que o problema da criminalidade não deve ser analisado de maneira apartada dos elementos socioeconômicos e que a sua solução, para além de uma resposta penal, vincula-se à expansão de direitos econômicos e sociais.

\section{REFERÊNCIAS BIBLIOGRÁFICAS}

BARATTA, Alessandro. Criminologia Crítica e Crítica do Direito Penal: introdução à sociologia do direito penal. $3^{\mathrm{a}} \mathrm{ed}$. Rio de Janeiro: Revan, 2002.

BEÇAK, Rubens. Democracia: hegemonia e aperfeiçoamento. São Paulo: Saraiva, 2014. BITTAR, Eduardo C. B. O direito na pós-modernidade. 2. ed. Rio de Janeiro: Forense Universitária, 2009.

BONAVIDES, Paulo. Do Estado Liberal ao Estado Social. 8a ed. São Paulo: Malheiros, 2007. FERREIRA FILHO, Manoel Gonçalves. Direitos Humanos Fundamentais. 11. ed. São Paulo: Saraiva, 2009.

FERNANDES, Newton; FERNANDES, Valter. Criminologia Integrada. $2^{\mathrm{a}}$ ed. São Paulo: Revistas dos Tribunais, 2002.

GENNARI, Adilson Marques; OLIVEIRA, Roberson de. História do pensamento econômico. São Paulo: Saraiva. 2009.

GOTTI, Alessandra. Direitos sociais: fundamentos, regime jurídico, implementação $e$ aferição de resultados. São Paulo: Saraiva, 2012.

JUDT, Tony. Um tratado sobre nossos actuais descontentamentos. Lisboa: Almedina, 2012. 
MAGAlHÃES, José Luiz Quadros de. Comentário do filme "A Vila" Disponível em < http://joseluizquadrosdemagalhaes.blogspot.com.br/2010/06/comentario-do-filme-vila.html>. Acesso em 30 mar. 2014.

MAGALHÃES, José Luiz Quadros de. Privatizar o sistema carcerário? Disponível em $<$ http://joseluizquadrosdemagalhaes.blogspot.com.br/2010/08/privatizar-o-sistemacarcerario.html> Acesso em 30 mar. 2014.

MORAIS, José Luis Bolzan de; STRECK, Lenio Luiz. Ciência política e teoria do estado. 6. ed. Porto Alegre: Livraria do Advogado, 2008.

SILVA, José Afonso da. Curso de Direito Constitucional Positivo. $25^{\mathrm{a}}$ ed. São Paulo, 2005.

SOARES, Mário Lúcio Quintão. Teoria do estado: paradigmas em face da globalização. 3. ed. São Paulo: Atlas, 2008.

WACQUANT, Luïc. As duas faces do gueto. São Paulo: Boitempo, 2008. 